\title{
'The risks are fairly clear' Interview with Christopher Balme
}

\author{
Radka Kunderová
}

Christopher Balme is Professor at Ludwig-Maximilians-Universität Munich where he also chairs the Department of Theatre Studies. His publications include Decolonizing the Stage: Theatrical Syncretism and Postcolonial Drama (Clarendon Press, 1999); Pacific Performances: Theatricality and Cross-Cultural Encounter in the South Seas (Palgrave Macmillan, 2007); Cambridge Introduction to Theatre Studies (CUP, 2008); The Theatrical Public Sphere (CUP, 2014) and The Globalization of Theatre 1870-1930: The Theatrical Networks of Maurice E. Bandmann, (CUP, 2020). He co-edited with Tony Fisher Theatre Institutions in Crisis: European Perspectives (Routledge, 2021). He is principal investigator of the ERC Advanced Grant 'Developing Theatre: Building Expert Networks for Theatre in Emerging Countries after 1945' and the German research group 'Krisengefüge der Künste: Institutionelle Transformationsdynamiken in den darstellenden Künsten der Gegenwart' (DFG).

Radka Kunderová, who currently runs the project 'Redefining the Agency: Post-1989 Crisis of the Czech and Former East German Theatre' at Freie Universität Berlin, asked Professor Balme about his views on theatre in the current pandemic situation, the crisis of German theatre and its post-1989 history.

The interviewee responded in writing to questions sent by email. The correspondence was carried out in English and finalised on 27 April 2021.

This interview is a part of the project which received funding from the European Union's Horizon 2020 research and innovation programme under the Marie Skłodowska-Curie grant agreement No. 837768. 


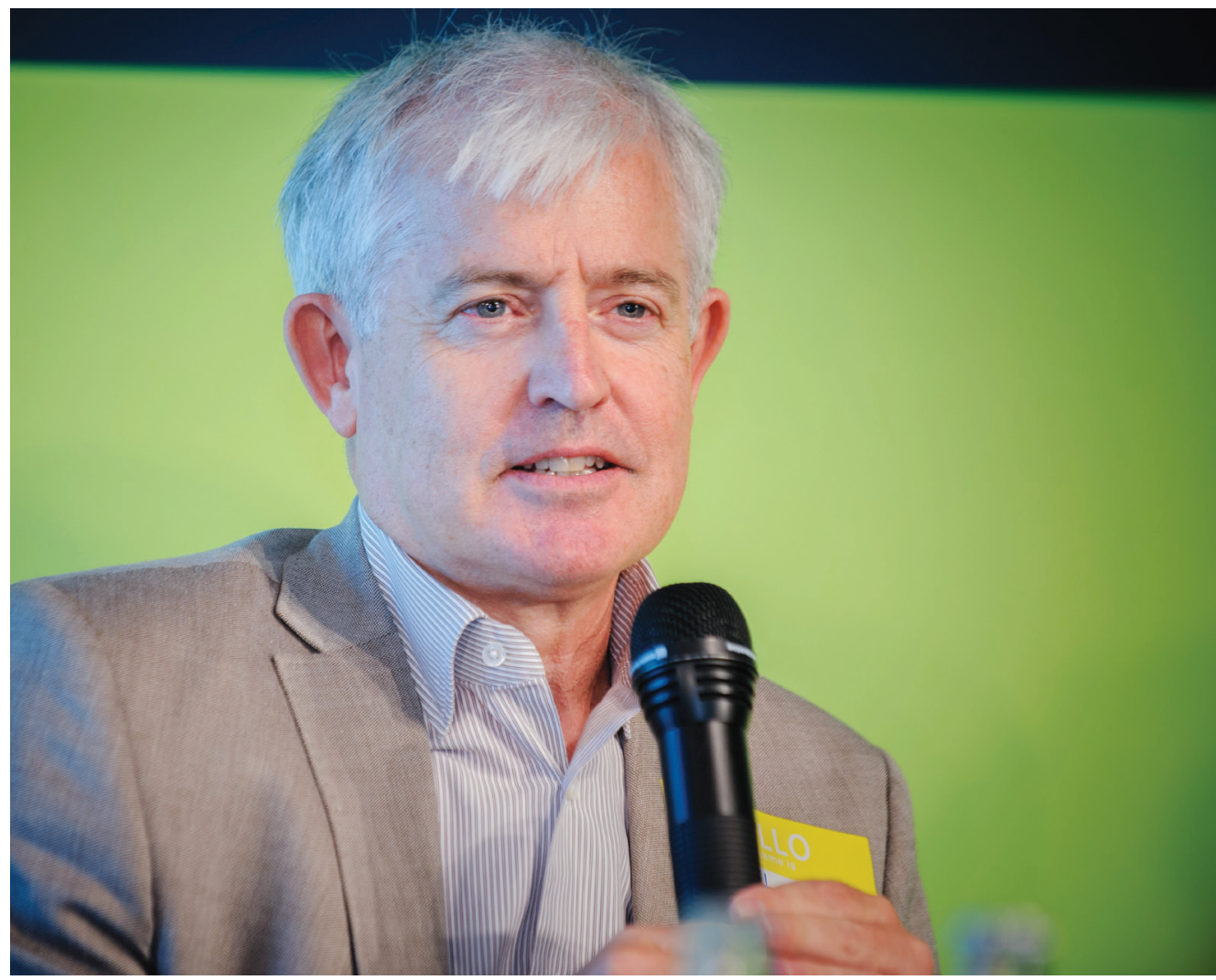

Prof. Dr. Christopher Balme (RÖHL 2013).

[RK] In your ongoing collaborative research project Krisengefüge der Künste, you have investigated effects of the COVID-19 pandemic on German theatre system. In a recent interview, ${ }^{1}$ you have introduced your team's hypothesis that the pandemic has accelerated the existing structural crisis in German theatre. What main factors, in your view, had caused such a crisis before the pandemic?

[ChB] One must speak of crises or a set of problems that configure to make up a crisis: what we call a Krisengefüge. We are investigating these factors along four axes, but there are, no doubt, more:

a) enculturation breakdown, precipitated by demographic changes (the age pyramid as well as migration). We hypothesise that certain practices of theatre-going that are transmitted into generationally are no longer necessarily intact. For this reason, theatres - this applies especially to opera, but not just to music theatre - are required to employ more and more professional specialists to act as a go-between between

1 See (BALME 2021). 
production and reception. This means that a primarily binary relationship has now changed or is increasingly changing into a triadic one. We see this everywhere as cultural institutions are required to provide more and more outreach;

b) the increasing pluralisation of the public sphere (through the multiplication of media, especially social media); this means that it is increasingly difficult for theatres to 'manage' their communication in and with the public sphere. Theatres are forced to employ an increasing number of people in the area of publicity and communication;

c) diversification of labour (especially the precarious effects of economic liberalism on patterns of work and employment) and the emergence of an independent theatre scene parallel to the so-called institutionalised theatres; the German-context contracts and publicly funded theatres were and still continue to be regulated by agreements, but these differ considerably within the larger institutions and create quite different working conditions for actors, dancers, members of the chorus, orchestra musicians et cetera. Now we have an increasing collaboration between public theatres and the independent scene, and these require another kind of contract altogether. This is creating considerable pressure within the publicly funded theatres;

d) the emergence of new aesthetic techniques or production processes entailing 'reformatting' and which no longer fit the old model of the theatre as play production. This also has repercussions on traditional theatrical labour. The increasing collaboration between the public theatres and the independent scene as leading to artistic experimentation, and the emergence of new forms that are called 'formats', with a nod to television formats. These do not fit into the traditional repertoire and ensemble system. While they still stand for minority performances, the numbers are increasing all the time. Especially popular are so-called 'citizens' stages', which involve amateurs, and therefore a situation of propinquity between professionals and amateurs.

[RK] Is it possible that some causes of the pre-pandemic crisis had been rooted in the early 1990s developments in German theatre after the end of the Communist regime in East Germany and following reunification of Germany?

[ChB] We don't see the end of the Cold War and the reunification of Germany as a primary cause. There was however considerable adaptation required in the former East Germany as the theatre system there, which was centrally financed, was forced to adapt to the west German model, where economic support comes either from the individual state or the local city. Some of the smaller towns had and continue to have problems funding their theatres which in some cases support opera, ballet, drama, and an orchestra under one roof. 
[RK] Looking back, do you consider the years 1989 and 1990 as 'watersheds' in the course of developments of the German theatre system and/or aesthetics?

[ChB] Institutionally, it was less of a watershed than might appear because the systems were relatively congruent, except for the funding question mentioned above. The current system emerged in stages during the Weimar Republic and reached 'completion', in the sense of being totally publicly funded, under the Nazis. The basic idea that every medium-sized to larger city should have a fully funded public theatre comprising the three main genres existed by 1945 already. In fact, publicly funded theatre flourished in all socialist countries and its structural foundations remain intact (more or less). What changed, of course, after 1989 was the degree of artistic freedom gained and the amount of financial support lost. It is really remarkable when you consider how many opera houses with orchestras Germany supports in comparison, say, to the United Kingdom. How many opera houses are there in the UK? Four or five I think for the whole country. Berlin and Munich together have five.

[RK] How do you see the 1990s period in German theatre, in hindsight?

[ChB] As for the whole country, the eastern parts of the country were forced to adapt much more than the western parts. There is good reason that the narrative of a 'hostile takeover' gained traction. So German theatre appeared differently, depending on which part of the country you were working in or attending as a spectator. The 1990s were also dominated by the whole question of collaboration with the old regime, and a number of well-known writers, artists, and theatre figures turned out to have collaborated quite closely as IMs (unofficial collaborators).

The 1990s was the decade in which postdramatic theatre began to take hold in Germany through a network of festivals and theatres. This was mainly touring theatre with guest performances, so it emerged very much on the margins and played only a minor role in the ensemble theatres. It is no accident that Hans Lehmann's eponymous book appeared in 1999 thus documenting events and trends of the previous decade (and beyond).

[RK] In current German theatre, is the difference between the former West German constituent states and the 'Neue Bundesländer' of the former East Germany still traceable in your opinion?

[ChB] On a systemic level the theatre landscape has become quite isomorphic. You will find in specific theatres differences that stem from the period before 1989. For example, the independent Sparte puppet theatre was sustained there at a number of theatres. That is in turn a very eastern European development. In the West, puppet theatre was almost exclusively private and directed at children. On the level of cultural politics, there were also specific developments such as in Saxony which passed a law on cultural matters (Kulturraumgesetz) already in the 1990s. This was unheard of in the 
West. There, cultural politics, if it existed at all, consisted mainly in the appointment of a new artistic director or conductor every five to ten years, i.e., in supporting the institutional status quo. This situation begins to change after 2000 when the federal government, the SPD/Green coalition government appoints a succession of state ministers for culture and media. This has led to a much more proactive kind of cultural politics within the bounds of the constitution, which really delegates cultural matters to the individual states. So now the differences are less between East versus West than between the individual states.

[RK] In your monograph The Theatrical Public Sphere (BALME 2014), you have highlighted the interrelation between theatre and the public sphere. Have the restrictions taken in response to the pandemic changed German theatre's relation to the public sphere and the public sphere's relation to the theatre? If so, how?

[ChB] In the absence of live performances it is very difficult to make any kind of prognosis. The relationship between theatre and the public sphere is very complex and involves the interaction of several 'actors' over a long period of time: theatre artists, the theatre-going audience, cultural politics, and, of course, the media. At the moment, we are in a kind of interregnum where there is too little interaction to judge if there has been a recalibration of the relationship or not. There still appears to be potential for scandals or shitstorms, as the public theatres continue to work, rehearse, and present their productions online. What we can observe, however, is a very active public sphere in relation to theatre after the pandemic. The discussions relating to the crisis have, in many cases, gained in intensity - perhaps because people have more time, or perhaps because the structural problems have become so glaring. It will be interesting to follow up on how this aspect of the theatrical public sphere may lead to far-reaching changes.

[RK] In the interview mentioned above, you argued that after the restrictions are loosened, the audiences will very probably be hungry for theatre and, also, theatre companies will keep the digital 'by-products' they developed in the pandemic era. That sounds as a potential positive impact of the Corona-crisis. In contrast, what are the main risks German theatre will face in the upcoming years, marked by the pandemic aftereffects, in your view?

[ChB] The risks are fairly clear. In the independent scene there is the real danger that the field has been decimated after such a long period of inactivity. This will not affect the established players but will certainly impact on the newer groups. The absence of the festival market for over a year is a serious problem. We simply do not know how the pandemic will evolve. There may be a fourth wave, for example, if some vaccines are ineffective. Then it is a question of balancing government regulations with audience desire and willingness to take risks. The older vaccinated audience which is habituated to theatre-going and probably has a subscription ticket will definitely be ready to go 'back in the water'. A more complex question pertains to the various forms of artistic 
labour in the theatres. Especially those freelancers (many actors, directors, designers) without fixed contracts have been exposed to a kind of highly precarious labour. Will they be prepared to resume their previous high-risk, low-paid professional lives?

\section{[RK] What steps should be taken to improve the situation of theatre in Germany?}

[ChB] I can only respond to this question on a very general level. I do not think the answer is more funding. Internationally speaking, the German theatre system is exceptionally well financed. But the system with its ensembles and repertoires is an exceptionally expensive way to produce theatre. It also produces massive inequalities which are not visible to the outside view but are very much a topic inside. The current tendency towards 'over-production' needs to be reviewed. The sheer number of productions should be a marker of success. There needs to be a better distribution of public funds between the public theatres and the independent groups.

\section{Bibliography}

BALME, Christopher B. 2014. The Theatrical Public Sphere. Cambridge: Cambridge University, 2014.

BALME, Christopher B. 2021. Nachdenken über ein anderes Theater [Thinking about Different Theatre]. Interviewed by LMU. Ludwig-Maximilians-Universität News (12. 3. 2021). [accessed on 28. 3. 2021]. Available online at https://www.lmu.de/de/newsroom/news-und-events/news/ nachdenken-ueber-ein-anderes-theater.html.

RÖHL, Stephan. 2013. Prof. Dr. Christopher Balme (Theaterwissenschaftler, LMU München) [online]. Konferenz „Theater und Netz“ der Heinrich-Böll-Stiftung in Berlin. 9. 05. 2013. Source: Konferenz: Theater und Netz. Author: Heinrich-Böll-Stiftung from Berlin, Deutschland. [accessed on 16. 10. 2021]. Available online at https://commons.wikimedia.org/wiki/ File:Christopher_Balme_-_Konferenz_Theater_und_Netz_(8868756023).jpg. 